\title{
NARRATIVAS POPULARES: O GRIÔ E A ARTE DE CONTAR HISTÓRIAS*
}

POPULAR NARRATIVES: THE GRIOT AND THE ART OF STORYTELLING

NARRACIONES POPULARES: EL GRIOTY EL ARTE DE CONTAR HISTORIAS

\author{
Denise Marcos Bussoletti \\ Doutorado em Psicologia pela Pontifícia \\ Universidade Católica do Rio Grande do Sul \\ Vagner de Souza Vargas \\ Mestrado em Ciências da Saúde pela Fundação \\ Universidade Federal do Rio Grande \\ Cristiano Guedes Pinheiro \\ Doutorando do Programa de Pós-Graduação \\ em Educação (PPGE-UFPel)
}

RESUMO: O Núcleo de Artes, Linguagem e Subjetividade, da UFPEL, desenvolve atividades acadêmicas e ações culturais na cidade de Pelotas/RS. Uma dessas ações é desenvolvida por uma griô do movimento negro local, que trabalha contando histórias sobre seus ancestrais africanos e as suas vivências pelo carnaval pelotense, cenário do qual emergem a maior parte de suas memórias. O objetivo deste trabalho é relacionar as atividades da griô junto aos nossos projetos nos marcos conceituais de uma Pedagogia da Fronteira e através daquilo que pactuamos como sendo uma Estética da Ginga. Ao contar suas histórias e realizar as suas oficinas, a griô permite-nos reafirmar a importância e a permanência da tradição oral, atualizando conceitos tais como o de diferença e diversidade cultural, possibilitando o reconhecimento do caráter múltiplo da identidade e da importância da educação como práxis transformadora e em constante transformação.

PALAVRAS-CHAVE: Educação. Pedagogia de fronteira. Estética da ginga. Griô.

ABSTRACT: The Nucleus of Arts, Languages and Subjectivities, from UFPEL, develops activities promoting academic knowledge and cultural actions in Pelotas, southern Brazil. One of those actions is developed by a griot, telling stories about her African ancestors and how those stories have survived for centuries in Brazil. The aim of this article is to describe the activities done by this griot with our projects connected to Border Pedagogy and Aesthetics of Ginga conceptual proposals. By telling stories and making workshops, the griot implements those concepts by promoting perceptions and significations related to concepts of difference, diversity and cultural heritage, as positive characteristics that constitute our society and, through it, the recognition that all these hues create the identity of our local population. The griot allows us to affirm the importance and surveillance of the oral tradition, renewing concepts as difference and cultural diversity, which allows to realize the multiple character of identity and the relevance of education as a praxis that could be transformer and in constant transformation.

KEYWORDS: Education. Border pedagogy. Aesthetics of ginga. Griot.

\footnotetext{
* Artigo recebido em
}

Aprovado em 


\section{a $r$ t i g o}

RESUMEN: El Centro de Artes, Lenguajes y Subjetividades, del UFPEL desarrolla actividades de promoción de los conocimientos académicos y las actividades culturales en la ciudad de Pelotas/RS. Una de estas acciones es desarrollada por una griot, contando historias sobre el trabajo de sus antepasados africanos y cómo han sobrevivido durante siglos en Brasil. El objetivo de este trabajo es describir las actividades de la griot con nuestros proyectos, relacionados con la Pedagogía de la Frontera y Estética de Ginga. Para contar sus historias y realizar sus talleres, la griot nos permite reafirmar la importancia y la permanencia de la tradición oral, actualizando los conceptos como los de diferencia y diversidad cultural, posibilitando el reconocimiento del carácter múltiplo de la identidad y de la importancia de la educación como praxis transformadora y que está en constante transformación.

PALABRAS CLAVE: Educación. Pedagogía fronteriza. Estética de Ginga. Griot. 


\section{1 | Introdução}

[...] e são coisas assim da nossa cidade, que eu lido, que eu ouço e lido... que a gente vivendo muitos anos,

[...] tem muita coisa também que eu conto

[...] também ligado ao antigo e agora

[...] tem coisas que eu invento na hora, quando eu vou fazer as oficinas, porque eu não tenho pedagogia, não sou professora,

a minha pedagogia é griô mesmo!

Dona Sirley ${ }^{1}$

Walter Benjamin, no conjunto de sua obra, auxilia-nos a melhor compreender a experiência humana na contemporaneidade. Mais especificamente, a narrativa enquanto experiência, ou enquanto luta contra o empobrecimento desta pelas atividades que foram sendo implementadas no marco industrial capitalista. Através desse autor, podemos considerar que a arte de narrar enquanto elo entre o passado, o presente e o futuro foi se extinguindo, delimitando os contornos daquilo que denominamos como "discurso não vivo".

Se, ainda por meio de Walter Benjamim (1984), asseguramos que contar uma história é sempre contar uma outra e, ao mesmo tempo, renovada história, somos levados a crer que existe uma ameaça de perda eminente da nossa capacidade narrativa na medida em que não mais existam as histórias que acompanhavam o trabalho manual de tecer, ou o trabalho agrícola de colher, por exemplo. Histórias que não somente acompanhavam o trabalho, pois imprimiam, através de um ritmo íntimo e articulado a capacidade de continuidade e de resistência tanto das narrativas, quanto dos narradores.

Consideramos importante reafirmar que o elemento de continuidade narrativo foi sendo desfeito com a modernidade capitalista. Se, atualmente, muito se escreve e escreveu sobre as narrativas, principalmente sobre as narrativas orais, em igual medida, não se verifica, especificamente no Brasil, o seu reconhecimento e a sua valorização enquanto garantias efetivas de salvaguardar a memória e os sujeitos por ela inscritos. Este reconhecimento e valorização fazem parte de um processo em constante disputa, tanto do ponto de vista acadêmico, quanto do ponto de vista das comunidades que possuem a oralidade como elemento principal de sustentação da sua identidade, da sua memória e da sua história.

Cabe salientar, no cenário das políticas públicas, o quanto este reconhecimento é recente no Brasil. Como ilustração disso, temos a implementação da convenção da UNESCO (da qual o Brasil é signatário), a previsão constitucional dos direitos culturais Art. 215 e 216 (BRASIL, 2011a) e a implementação de políticas referentes ao reconhecimento e à valorização do patrimônio cultural brasileiro (a instituição do Registro dos Bens Culturais Imateriais Brasileiros e o Plano Nacional de Cultura²) que possibilitaram e prometem também promover a salvaguarda do patrimônio imaterial no país. Neste cenário, encontramos também em exercício o Instituto de Patrimônio Histórico e Artístico Nacional (IPHAN), órgão vinculado ao Ministério da Cultura (MinC) do Brasil, como a instituição responsável, entre outras ações, pelo inventário, registro e pela elaboração de planos de garantia e proteção do patrimônio imaterial no país (PINHEIRO, 2013).

No entanto, em que pese a riqueza da composição étnico-cultural brasileira e os inúmeros e singulares territórios por onde nascem e se gestam as pessoas e suas histórias, enquanto expressões de múltiplos conhecimentos e da resistência da memória, consideramos que a proteção e a valorização das narrativas orais ainda são insuficientemente amparadas pelas políti-

\footnotetext{
${ }^{1}$ Fala da griô Dona Sirley. In: PINHEIRO, 2013.

${ }^{2}$ O Plano Nacional de Cultura, aprovado pela Lei Federal n 12.343, de dezembro de 2010, teve suas metas definidas em dezembro de 2011. São ao todo, 53 metas a serem implementadas até 2020 (BRASIL, 2010; BRASIL, 2011b).
} 
cas públicas necessárias. O Brasil possui um vastíssimo patrimônio imaterial que se manifesta através das narrativas e dos narradores desde as grandes cidades até os pequenos povoados no campo. Pode-se assim facilmente imaginar a infinidade de "conhecedores", mestres, contadores de histórias, saberes e expressões populares e tradicionais que não estão sob a proteção dos instrumentos legais, nem amparados por políticas públicas de valorização, reconhecimento e de melhoria das condições de vida. No entanto, esses sujeitos existem e persistem, estão nas cidades, nos bairros, nas pequenas e grandes comunidades.

Partindo dessa constatação e da necessidade de pesquisa e intervenção, o Núcleo de Artes, Linguagem e Subjetividade (NALS), da Universidade Federal de Pelotas (UFPEL), desenvolve várias atividades acadêmicas e ações culturais na cidade de Pelotas/RS. Uma dessas ações é desenvolvida através e em conjunto com a griô ${ }^{3}$ Dona Sirley. Parte central do trabalho de Dona Sirley junto ao núcleo consiste em contar histórias sobre seus ancestrais africanos e a sua história pessoal articulada com a lembrança dos lugares e eventos por ela vividos, mantidos e que através de uma metodologia própria são repassados aos ouvintes. Trata-se de um ritual singular e de encontros entre gerações que são possibilitados por meio das ações e atividades realizadas. Neste trabalho, a memória acontece como experimentação e celebração, num contexto onde podemos vivenciar a potencialidade e a força das narrativas populares e, especificamente, da oralidade como fonte de acesso aos registros de importância ímpar. Esta é a prática e algumas das considerações em torno desta que enfocaremos no decorrer deste artigo.

Antes, porém, é necessário informar o contexto acadêmico em que essas atividades se efetivam. Destacamos que as ações propostas pelo NALS fazem parte do Programa Fronteiras da Diversidade (PFD) ${ }^{4}$ que articula vários projetos distintos, mas que possuem como unidade temáticas sobre diversidade e tolerância, destacando-se, assim, um projeto central originalmente chamado de "Contadores de Histórias". Esse projeto tem por objetivo resgatar a identidade cultural de grupos periféricos através de debates, eventos, shows e workshops, tendo as artes e a cultura como campo de trabalho. Essas atividades são apreendidas partindo do que chamamos "Estéticas Marginais" ou ainda "Estéticas Periféricas". De forma bastante genérica, o conjunto das ações busca promover a sua visibilidade e o exercício emancipatório da cidadania pela arte e cultura (BUSSOLETTI; VARGAS, 2013). Em síntese, a intenção primeira é a da construção de espaços "de celebração da memória", lugares onde o espectador é também um narrador, um contador de histórias e ao mesmo tempo é também a obra, ou a história, enquanto ação e intervenção criadora. Essa matriz de concepção é aliada à convicção de que a memória pode se constituir como um lugar de encontro de estéticas aparentemente inconjugáveis e que, por sua vez, através da arte, podem conduzir a itinerários mutáveis, de acordo com a rede estabelecida pelo espectador/narrador no diálogo com a obra/história e sua multiplicidade de significações (PINHEIRO; BUSSOLETTI; GILL, 2010; BUSSOLETTI; PINHEIRO, 2011; HAERTER, 2011; PINHEIRO; BUSSOLETTI; COSTA, 2011).

Articulado com o projeto "Contadores de Histórias" está o grupo de pesquisas "Narrativas Cotidianas: Identidade, Representação e Cultura" que, através da linha de pesquisa "Narrativas Populares", busca estabelecer o diálogo entre diferentes formas de conhecimentos, os produzidos pela universidade e os conhecimentos populares, expandindo perspectivas identitárias e considerando a diversidade como um elemento estrutural e discursivo (BUSSOLETTI, 2008). Esses projetos buscam produzir inovações práticas e teóricas através do encontro com diferentes territórios a partir da perspectiva da construção de alianças que objetivam pensar a universidade

${ }^{3}$ O termo griô será tratado em uma seção posterior e no contexto deste trabalho será aproximado da imagem e da função do contador de histórias.

${ }^{4}$ O Programa Fronteiras da diversidade foi classificado e coberto pela proclamação No. 4 pelo Programa de Extensão Universitária, PROEXT 2011 - Ministério da Educação e Cultura, da Secretaria para Educação Superior, do Governo Brasileiro. Desenvolve suas atividades desde 2011 na UFPEL. 
e a sociedade como espaços para a discussão e materialização de transformações possíveis (BUSSOLETTI, 2008; BUSSOLETTI; VARGAS, 2013).

Foi nesse contexto que se deu o encontro com Dona Sirley, a mestra griô, do movimento negro da cidade de Pelotas/RS, uma senhora contadora de histórias, de 77 anos, que trabalha contanto as histórias de sua ancestralidade pelas antigas charqueadas da cidade e de suas próprias vivências pelo carnaval local, cenário a partir do qual emergem a maior parte de suas memórias. Dona Sirley é uma costureira aposentada que mora na periferia da cidade. Além de griô, é uma ativista cultural, que participa de diversos grupos de promoção e valorização do negro, do idoso e de trabalhos com crianças, além de ser uma reconhecida carnavalesca pelotense.

Foi a partir do trabalho com Dona Sirley que, por meio da universidade e através do NALS, instituímos um campo de pesquisa mais amplo onde se situam questões como: a prática das narrativas populares pode ser entendida como um processo educativo e de resistência? Como se verifica/possibilita essa resistência? Como essas narrativas podem contribuir para a compreensão de novos e necessários processos educativos? Considerando isso, o objetivo deste texto é mostrar parte dessas questões, articulando as atividades da griô Dona Sirley no NALS, com as propostas de discussão de um marco conceitual que se gesta pelos contornos daquilo que instituímos como sendo uma Pedagogia da Fronteira e de uma Estética da Ginga. Para melhor atingir nossos objetivos, destacaremos, brevemente, na próxima seção, as origens do termo griô, bem como parte do papel do griô no cenário social.

\section{2 | Contadores de histórias: os griots, a griô e a memória viva}

Ao seu modo, os contadores de histórias mantêm, em sua memória, saberes e fazeres culturais, passados de geração em geração, ensinados de pais para filhos, de avós para netos, de velhos para jovens. Na história africana, segundo Ki-Zerbo (1982), as fontes para o seu conhecimento sustentam-se sobre três pilares: os documentos escritos, a arqueologia e a tradição oral. Esse autor considera ainda que, junto com o testemunho escrito e o arqueológico, a história oral tem se transformado numa importante fonte para a história africana. Segundo o autor, a história oral é contada e preservada pelos griots: "velhos de cabelos brancos, voz cansada e memória um pouco obscura, rotulados às vezes de teimosos e meticulosos." (KI-ZERBO, 1982, p.27). Além disso, também o autor refere que, ao encerrarem boa parte do conhecimento e das tradições africanas, cada vez que morre um desses guardiões dos saberes populares, é como se uma fibra do "fio de Ariadne" se rompesse. Nessa perspectiva, as histórias épicas, as genealogias, as guerras, as tradições, o cotidiano [...] contado e cantado pelos griots, são a expressão da cultura e da identidade desses povos (PINHEIRO, 2013).

Amadou Hampâté Bá (1982) destaca também a importância da oralidade para a apreensão da história da África. Para ele, é impossível tratar da tradição sem fazer referência à importância da tradição oral na África. Além disso, distingue, nessa tradição, os chamados tradicionalistas e os griots propriamente ditos. Os tradicionalistas são os considerados mestres em uma arte ou ofício (ferreiros, tecelões, pastores, caçadores, pensadores, entre outros) ou são aqueles que possuem conhecimentos de muitas artes e ofícios (sobre as plantas, solo, água...) mestres naquilo que denomina como "ciência da vida". Em Bambara, esses mestres são chamados de Doma ou Soma, de Silatigui, Gando ou Tchiorinke, palavra que pode ser traduzida como "conhecedor". Esses mestres são verdadeiras autoridades, são considerados os guardiões da palavra, os detentores da memória viva do povo africano, transmitida através da tradição oral. E os griots, na terminologia francesa, ou dieli, em bambara, são animadores públicos, contadores de histórias, músicos, diplomatas, genealogistas ou poetas. Percorrem suas comunidades, regiões e os países, contando e cantando suas histórias, em buscas de informações para suas genealogias 
ou em alguma missão diplomática. A tradição lhes confere um status diferenciado dos tradicionalistas, enquanto estes têm como princípio o respeito à verdade, os griots têm o direito de se manifestarem sem o compromisso ou atenção com a veracidade de suas histórias, podendo inventar ou transformar fatos, pois nenhum ouvinte lhe imputará falta grave (PINHEIRO, 2013).

Transportando essa distinção para a cultura afro-brasileira e considerando ambos como depositários da tradição da África Ocidental, em nosso trabalho assumimos o tratamento destes como griots ou griôs, pois Dona Sirley é uma nomeada griô de tradição oral. Isto possibilita estabelecer uma relação entre o griot histórico africano e o griot brasileiro, aproximando Dona Sirley dos "velhos de cabelos brancos" e de "memória um pouco obscura" descrita por Ki-Zerbo (1982, p.27), ou mesmo com os contadores de histórias que pacientemente transmitem seus conhecimentos "de boca a ouvido, de mestre a discípulo, ao longo dos séculos", como ensinou Hampâté Bâ (1982, p.181). Partindo dessa concepção, na próxima seção buscaremos esboçar alguns elementos importantes acerca da perspectiva ética e estética defendidas.

\section{3 | Contadores de histórias: a oralidade em trama}

Pela oralidade, uma rede narrativa se converte em trama na medida em que acata o sentido intencional e provocativo de desestabilização das expressões culturais hegemônicas. Um sentido ético-estético que se articula pela imbricação, pelo cruzamento dos fios de uma história que também se faz pelas fissuras, pelas margens, pelas bordas e que como não poderia ser diferente, mistura imagens, linguagens e referências, almejando uma síntese imagética que traduza a ambivalência e a contradição, produzindo rupturas com os estados de obviedade das histórias que foram sendo estruturadas alheias à participação e a expressão de traços da cultura popular genuínos. Pela oralidade, uma trama se faz também pelas atitudes de "crítica permanente" onde a experimentação e a opção pela construção coletiva se abrem como possibilidade cúmplice e ativa. Contar histórias é, portanto, tramar histórias explorando todas as múltiplas faces que nos remete a operacionalização destas significações e sentidos (BUSSOLETTI, 2008).

Através da possibilidade da experimentação da oralidade como trama, almejamos "exercícios para um comportamento", conforme dizia Hélio Oiticica, operacionalizados através da participação e da transmutação do espectador em narrador cuja autoria é manifestada através da vivência como manifestação da vida em direção da atividade criativa (JACQUES, 2003). Entre a imaginação e o êxtase, a proposta é "sul-realizar" comportamentos, desterritorializar as possibilidades reprimidas e/ou ocultas e conceder o espaço educativo na direção da transgressão e da resistência de práticas alternativas, não submissas as concepções históricas e políticas calcadas na tradição mantida pelo culto das regularidades e estabilidades consumíveis como produtos de uma ordem contestável e alheia a aspiração que se junta a um velho/novo coro que contando histórias re-diz: Experimentem! "Nosso norte é o sul!". (BUSSOLETTI; PINHEIRO, 2011).

Dizendo isso, podemos também salientar que as relações entre a palavra oral e a escrita nunca foram pacíficas, uma vez que uma vai na contramão das idiossincrasias da outra. O que queremos dizer é que para a liberdade discursiva e expressiva do oral não corresponde exatamente o mesmo princípio na palavra escrita, pois a escrita se coloca como o duradouro, o definitivo em alguns casos (FERNANDES, 2008). O oral tem uma finalidade diversa, que é marcada pelo contato persuasivo e mais direto entre os locutores, sendo um texto que pode ser reelaborado no ato de sua produção/recepção. Contrariamente, a escrita, ao se enquadrar na durabilidade do tempo e espaço, se destina muito mais ao canônico, podendo transitar entre várias culturas com a autoridade de quem a impõe como o elemento ordenador, claro que do ponto de vista hegemônico. Por isso, a escrita serve com melhor aproveitamento à concepção clássica de ciência porque ordena mais coesivamente o sintagma, coisa que a oralidade não se adequa por 
seu caráter digressivo e performático, ou seja, em especial as narrativas orais são marcadas por narrativas de encaixe e pela complementação do corpo à voz, ou seria a complementação da voz ao corpo? (FERNANDES, 2008).

A autoridade política de cada modalidade talvez seja mais determinante na medida em que a escola e outros segmentos afins legalizam a escrita como "a língua" e reservam ao oral o estigma de "errado", o que não é novidade. A escrita parece se constituir em mais racional do que a oralidade e, por essa razão, é mais aceita pelo discurso científico. Isso porque, no caso específico da história oral, pode-se considerar que é uma história construída em torno de pessoas (FERNANDES, 2008).

Nesse sentido, é bom lembrar que elidir o pensamento à fala requer um longo processo para as populações tradicionais e empobrecidas, pois a participação do indivíduo na condição de enunciador de seu discurso oralizado pressupõe vencer os estágios de criar, defender, argumentar, opinar sobre um conhecimento muitas vezes posto de lado pela cultura hegemônica (FERNANDES, 2008). Se por um lado as narrativas orais de histórias de vida são importantes para a releitura da realidade, não é menos verdade que devemos "arrumar" as versões orais para melhor compreendê-las. Nesse caso, arrumar não significa só colocar o oral na camisa de força do escrito, o que é necessário ainda na academia. É certo que a necessidade de transcrição, imposta pela tradição científica para o estudo do texto narrativo oral, por si só é uma contradição em função de que a epistemologia universitária credita maior factualidade ao escrito. A coerência no texto oral não é a mesma coerência do texto escrito (FERNANDES, 2008).

No caso do oral, a performance é o que engloba o todo para dar a medida expressiva da narração, ou seja, palavra e corpo estão enraizados na história, seja no tom da voz ou na escritura do gesto e do semblante. Assim é que o que pode aproximar e estreitar o oral e o escrito é o gênero dramático, a escritura teatral, porque entre o narrador e o dramaturgo a diferença é de sentido: enquanto este escreve para encenar, aquele encena o que será escrito pelo pesquisador. E, aqui, talvez resida a riqueza da narrativa oral, pois ela é escrita a duas mãos, ou melhor, entre a voz e a mão, em duas modalidades (FERNANDES, 2008). Avançando através dessa compreensão, podemos, agora, voltar para o encontro com Dona Sirley e os desdobramentos dessas reflexões.

\section{4 | Dona Sirley e o Nals: histórias e oficinas}

Por meio do NALS, Dona Sirley desenvolve as oficinas de "contação de histórias". A "contação de histórias" é um termo que foi tomado de empréstimo das ações formativas de comportamento leitor, notadamente daquelas que possuem suporte não somente os textos literários. A apropriação e adequação do conceito foram sendo articuladas nas trocas entre a griô e o grupo. Essas oficinas de "contação de histórias" decorrem, assim, da compreensão da centralidade do papel das narrativas orais e dos narradores na luta contra o empobrecimento da experiência, tal como Walter Benjamin sugere e cuja referência já fizemos em seção anterior deste texto. Sintetizando, poderíamos dizer que é uma estratégia de formação e valorização das identidades sociais no diálogo com a cultura, em sua pluralidade significativa, tendo a memória como fio condutor na compreensão que os sujeitos possuem ou podem possuir tanto de si, quanto do mundo.

Das oficinas, participam os mais diferentes grupos e o ambiente é escolhido de acordo com os objetivos específicos de cada uma. Existem, assim, oficinas que acontecem em instituições de assistência social para crianças, jovens e idosos, outras que são realizadas nas escolas, nas praças, no calçadão da cidade, em eventos acadêmicos e culturais, em livrarias, cafés e outros que são escolhidos de acordo com as necessidades das ações pretendidas. No momento da escrita deste texto, por exemplo, Dona Sirley está de "malas prontas" junto com um estudante, membro do NALS, para ser uma das duas representantes do Rio Grande do Sul na "Teia", que é 
o encontro nacional dos Pontos de Cultura e de encontros nacionais das entidades que integram o Programa Cultura Viva, do Ministério da Cultura, através da Secretaria da Diversidade Cultural e que, em 2014, acontecerá na cidade do Natal/RN. Porém, no cenário dos próximos meses, a mestra já confirmou a participação no Fórum Latino-americano de Memoria e Identidade que acontecerá em Montevidéu, Uruguai e que mais uma vez Dona Sirley irá acompanhando, como protagonista das apresentações do Núcleo. Citamos estas duas situações específicas somente para ilustrar o quanto a agenda da mestra é ampla e múltipla e quem a conhece confirma. É ela quem estabelece o ritmo sempre urgente para que tudo aconteça com o maior público e o mais rápido possível.

Da agenda para a dinâmica de cada oficina, cabe destacar que Dona Sirley costuma chamar os participantes para fazerem parte de suas performances e, então, começa a tramar os primeiros fios de suas histórias, relatando fatos, mitologias recriadas, traços, lembranças e características culturais de seus ancestrais africanos, histórias dos tempos das charqueadas (parte da história local) e da própria tradição do carnaval no município de Pelotas. Por meio das suas histórias aparentemente simples, Dona Sirley ressalta questões das diferenças de etnia, gênero e de formação social da região sul do Rio Grande do Sul. Além das histórias, Dona Sirley também compõe músicas onde imprime essas questões perpassadas por fatos históricos através de sua interpretação e autoria. Essas músicas são utilizadas durante as oficinas como meio e elo de integração com os participantes.

Além de contar e cantar suas histórias, Dona Sirley ressalta particularmente o valor na lembrança de uma Pelotas negra, geralmente esquecida de ser valorizada pela "história oficial" através da tradição caucasiana européia, acentuada nos registros históricos escritos locais. Além disso, a mestre griô, durante essas atividades, organiza o que podemos considerar como sendo um ritual onde são confeccionados objetos e executadas atividades com o intuito de ir tecendo as histórias e músicas em algo material, como uma colcha de retalhos, por exemplo.

Entre uma história e/ou uma música e outra, a griô Dona Sirley convida os participantes para dançarem e/ou encenarem o que está sendo contado naquele momento. Facilmente, os participantes entram nesse universo lúdico que a mestra vai criando lentamente ao longo da oficina.

Em atividades como a oficina de fuxicos ${ }^{5}$, a griô ensina a técnica de confecção de fuxicos e de como construir outros objetos e vestimentas a partir deles. Mas ela vai além disso, estimulando os participantes a trocarem histórias para cada novo fuxico criado. Estas oficinas, normalmente são constituídas de três momentos: a apresentação, a troca de histórias e a despedida. $\mathrm{Na}$ apresentação, ocorre a entrada da mestra utilizando uma canção escolhida e cantada por ela e ensinada no decorrer aos participantes. Tais canções, na maior parte das vezes, são canções populares e, em cada canção, uma lembrança é evocada e partilhada com o grupo. Logo após, as histórias vão sendo trocadas durante a construção dos fuxicos feitos por todos. Por fim, a saída da mestra acontece através de um canto coletivo caracterizando a despedida e a finalização do trabalho.

Outras atividades desenvolvidas por Dona Sirley são as oficinas com as crianças, como parte do projeto da "Confraria do Fuxico", onde além de contar as suas histórias e de ler outras histórias, as crianças ajudam a griô a costurar uma saia com fuxicos, na qual cada uma adiciona um fuxico à saia e dentro dele insere uma palavra relacionada a uma história que conheça. Para cada nova história, uma palavra e um fuxico são adicionados. Nesse trabalho, a relação entre a

\footnotetext{
${ }^{5} \mathrm{O}$ fuxico é uma técnica artesanal que aproveita sobras de tecidos para fazer uma pequena trouxinha de pano. Sozinho, o fuxico pode ser utilizado como adorno, costurado um a um, pode cobrir almofadas, bolsas, roupas e uma infinidade de outros objetos. Segundo o conhecimento popular, o fuxico surgiu nas senzalas, quando, as escravas ao costurarem os retalhos desprezados pela casa-grande, ficavam conversando sobre o dia-a-dia (FAJARDO; MATHIAS; AUTRAN, 2002, p. 74).
} 
música e a literatura se fazem fortemente presentes. Entre as leituras preferidas estão as crônicas do escritor Eduardo Galeano, como a "A casa das palavras", do Livro dos Abraços.

Outras atividades caracterizam-se por "oficinas de confecção de bonecas de pano" que fogem aos estereótipos das bonecas vendidas pelo comércio em geral e remontam a uma tradição quase perdida e/ou esquecida. Cada boneca confeccionada pelo grupo surge a partir de uma das histórias contadas durante a oficina. Cabe salientar que essas bonecas são criadas com traços e características e relacionadas à cultura de matriz africana.

Já nas oficinas de "histórias de amor e carnaval", a griô Dona Sirley insere e revive os elementos do carnaval, com os participantes vestindo indumentárias relacionadas a personagens típicos dos carnavais antigos, como por exemplo, as baianas, mascarados, palhaços, entre outros. Nessas atividades, o foco são as histórias de carnaval, relacionadas à formação histórica da cidade de Pelotas, intercaladas por momentos onde são cantadas e dançadas algumas marchinhas dos antigos carnavais.

Em outras atividades, Dona Sirley, juntamente com os integrantes do NALS, realizam o "Cortejo Griô". Nessas atividades, reúnem-se vários agentes sociais e culturais da cidade, em especial, representantes do movimento negro para desenvolverem atividades itinerantes pelo centro histórico da cidade, divulgando a cultura de matriz africana, como rodas de capoeira, sambas de roda, apresentações de dança, exposição de fotografias que trazem imagens das antigas charqueadas e dos primeiros africanos a chegarem ao Rio Grande do Sul e também exposição de estandartes e camisetas históricas de várias escolas de samba locais. Todas essas atividades possuem o mesmo fio narrativo e fluem na perspectiva da "contação de histórias", referida anteriormente.

O caráter informal das atividades desenvolvidas pela griô Dona Sirley se manifesta nas experimentações e possibilita ao participante transitar entre espaços e conceitos que algumas formalizações mais institucionalizadas poderiam dificultar. Além disso, suas atividades conseguem abordar e tocar os participantes de uma maneira leve, simples, rápida e envolvente, trazendo todos para o universo vibrante de suas histórias. Com o seu carisma, Dona Sirley consegue estimular para que todos contribuam, ao trocarem e acrescentarem suas histórias em um jogo prazeroso, ressaltando na forma final o valor da riqueza da diversidade cultural brasileira.

\section{5 | Interculturalidade, educação do sensível e diversidade cultural: a contação de histó- rias por entre a estética da ginga e a pedagodia da fronteira}

As práticas discursivas instituem repertórios em torno da diversidade e da diferença cultural com fortes implicações no campo educativo. No marco das orientações multiculturais, as representações discursivas acerca do reconhecimento da diversidade cultural e étnica no Brasil (como também na América Latina) acabam muitas vezes impondo um conceito de diversidade estigmatizado e gerenciador de conflitos identitários. O regime de representações dominante tende a essencializar e naturalizar as identidades culturais (BUSSOLETTI; YÁNEZ, 2012). É neste âmbito e contexto que a interculturalidade na América latina, especificamente no que se refere à educação, se faz como categoria em construção.

Algumas práticas educativas têm, em sua natureza, a fragmentação, dos conceitos e conteúdos, negligenciando o espaço educativo como agenciador e formador da identidade plural pela diversidade cultural. Mediar o conhecimento significa, assim, compreender o ser humano, através de novos padrões éticos e estéticos. É necessária a produção de um conhecimento sensível, com a vida e com tudo que faz sentido e gera mudanças na produção de significados (SILVA, 2012). Nessa perspectiva, nós precisamos perceber a importância de que as práticas educativas levem em conta a abordagem sensível desde a sua própria constituição como educadores. 
Sobre esse tema, Duarte Júnior (2001, p.206) afirma que "na verdade, uma educação sensível apenas pode ser desenvolvida por educadores cujas sensibilidades foram desenvolvidas".

No entanto, a educação através do sensível às vezes é considerada menos importante (PILLOTTO, 2007). Nesse sentido, perguntamos: seria possível um ensino e aprendizado pela razão ser separado da sensibilidade no século XXI?

A educação do sensível é um caminho para evitar o aumento da perspectiva unilateral do mundo que o homem moderno tem devido ao impacto tecnológico, permitindo a ocorrência da integração dele com ele mesmo e com a sociedade em sua diversidade cultural. O conhecimento sensível carrega um processo de ver o mundo e as relações no limiar do racional e emocional (PILLOTTO, 2007). Quando nós pensamos sobre as práticas educativas que dialogam com a estética da sensibilidade, nós observamos que o próprio significado da educação agrega mudanças, desde a escola deixar de desempenhar o papel de mera transmissora de conhecimentos, a comprometer-se com a formação de indivíduos capazes de articular essas questões com a prática e ter atitudes compatíveis com a vida em sociedade (SILVA, 2012).

Os sinais subjetivos em comunicação também ocorrem pela via das emoções - a expressão de um olhar, o movimento corporal, a tonalidade vocal e também outros sinais que comunicam o indizível. Assim, a razão está relacionada ao sensível, posto que ambos desenvolvem processos de aprendizagem. A apreensão emocional é fundamental à compreensão, conhecimento e comunicação. Em outras palavras, os professores devem desenvolver seus processos emotivos para se compreenderem, para compreenderem os estudantes (SILVA, 2012). Em relação a esses argumentos, podemos citar o que é descrito nos Parâmetros Curriculares Brasileiros:

O conhecimento de arte abre perspectivas para o estudante ter uma compreensão de mundo em que a dimensão poética é presente: arte ensina que nossas experiências geram um movimento de transformação permanente necessário para reordenar os referenciais o tempo todo, sendo flexível. Isso significa que criação e conhecimento são inseparáveis e a flexibilidade é fundamental ao aprendizado (BRASIL, 1998, p.20).

O processo de criação e realização corresponde a um caminho de desenvolvimento pessoal. Os contadores de histórias, assim como os griôs, podem crescer através de suas vidas, crescendo para níveis maiores e mais complexos, para os quais existem latentes em suas potencialidades. Esse processo não é estacionário. Ele é dialógico, uma vez que é inserido no meio cultural. Essa relação permite a essas pessoas repensarem e agirem frente a novas situações comumente inesperadas e imprevisíveis (PILLOTTO, 2007). Ainda sobre esse aspecto, enfatizamos o que Buoro (2002) refere quando compara as artes e a produção do sensível:

Se arte é produção sensível, se ela é sobre a relação da sensibilidade com a existência humana e experiência capaz de gerar um conhecimento de diferentes naturezas do que a ciência propõe, é na valorização dessas sensibilidades numa tentativa de desenvolvê-la no mundo e para o mundo devolvê-la, que nós inegavelmente contribuímos para um projeto educacional, no qual a educação atua como papel chave e não apenas participa como um adjuvante (BUORO, 2002, p.41).

Uma pedagogia que foca seu compromisso para o reestabelecimento da formação pedagógica, mantendo o espaço para perguntas, mais do que para respostas conceituais e finalizadas, amparando a experiência radical da diversidade e da diferença, aproximando-se e diluindo as linhas que às vezes separam e criam, infelizmente, as fronteiras intransponíveis, é o que nós assumimos como Pedagogia da Fronteira (BUSSOLETTI; VARGAS, 2013). Obviamente, a base desses conceitos advém dos diálogos com o conceito de Pedagogia de Fronteira, proposto por Giroux (1992) e o de Identidade de Fronteira, referido por McLaren (1999). 
A compreensão desse processo contribui e acaba revelando estéticas emergentes, derivadas de uma mestiçagem e os cenários, nos quais a interculturalidade lida, configura o que nós também defendemos como "Estética da Ginga" (BUSSOLETTI; VARGAS, 2013). A Estética da Ginga se desenvolve a partir do trabalho conceitual de Hélio Oiticica (1939-1980). Artista brasileiro revolucionário que, através do seu trabalho experimental e inovador, tem sido reconhecido internacionalmente. Oiticica não aceitava definições e conceitos estanques. Por esse motivo, questionava e extrapolava o seu status como artista. Revolvendo conceitos, Oiticica assumiu que não havia se tornado um artista, mas alguém que permitia às pessoas emergirem em seus estados de criação peculiares, elaborando propostas que buscavam o que está além da arte, à qual ele denominou "intervenção" (BUSSOLETTI; VARGAS, 2013).

Para entender a proposta de Oiticica, nós precisamos referenciar o conceito de "anti-arte". O princípio de "anti-arte" não é a imposição, para o espectador, de ideias e estruturas finalizadas, mas buscar descentralizar as artes, movendo-as do campo intelectual e racional para o campo de criatividade, experimentação, descoberta, participação, algo que transfigura em outras ordens de significação (BUSSOLETTI; VARGAS, 2013).

Antiarte - compreensão e razão de ser do artista, não mais como um criador para a contemplação, mas como um motivador para a criação - a criação como tal se completa pela participação dinâmica do espectador, agora considerado participador. Antiarte seria uma completação da necessidade coletiva de uma atividade criadora latente, que seria motivada de um determinado modo pelo artista: ficam, portanto invalidadas as posições metafísicas, intelectuais e esteticistas [...] É, pois, uma realização criativa o que propõe o artista, realização esta isenta de premissas morais, intelectuais ou estéticas - a antiarte está isenta disso -, é uma simples posição do homem nele mesmo e nas suas possibilidades criativas vitais. O "não achar" é também uma participação importante (OITICICA, 2003, p.110).

Oiticica rompe definitivamente com a ideia do espectador passivo, um mero assistente e torna-o, através da sua arte, um acionador de vivências. Transfigura expectador em "participador", esse sujeito que dança no espaço e atravessa o tempo dando plasticidade à obra que desta forma pode ser reconhecida também como experiência coletiva. Participador e obra tornam-se, assim, inseparáveis, produtos e produtores de outra premissa estética (BUSSOLETTI; VARGAS, 2013).

Considerando isso, nós, do NALS, defendemos a possibilidade de experimentação artística pela educação, como uma teia que é realizada por entre as fronteiras. Nós almejamos "exercícios para um comportamento", como dito por Oiticica, operacionalizados através da participação e transmutação do espectador em narrador, cuja autoria é manifestada pela vivência, como uma manifestação de vida na direção da criatividade ativa. Entre imaginação e êxtase, essa proposta desterritorializa comportamentos e possibilidades suprimidos e/ou escondidos, encaminhando o espaço educativo no sentido de transgressão e resistência de práticas alternativas, não submissivas aos conceitos adquiridos a partir da tradição histórica e política mantida pelo culto das regulares estabilidades consumíveis como produtos de uma forma contestável (BUSSOLETTI; VARGAS, 2013).

Também consideramos necessário dizer que nossa proposta, trabalhando com o PFD e o NALS, caminha justamente nesse sentido, desterritorializando comportamentos e normas, transgredindo fronteiras impostas, expondo-as apenas como material para discussão, reflexão e debate entre todos os elementos, agentes que as constituem, para, assim, dentro de suas singularidades, extrapolar sua auto percepção e propor outras alternativas de alteridade, onde o respeito emerge como resultado de um processo educativo (BUSSOLETTI; VARGAS, 2012). Portanto, nós acreditamos que nossas práticas com o PFD e o NALS criam oportunidades para 
apreciação das peculiaridades que constituem os sujeitos sociais nas suas diferenças, deslocando-os no total exercício de alteridade, tornando possível, a eles e a nós, a compreensão de muitas fronteiras que podem ser intercruzadas por meio do conhecimento. Ao propor o conceito de diversidade de maneira mais ampla, nós percebemos que os sujeitos também acabam empurrando as fronteiras de identidade que, no jogo de re-cognição, os constituem como indivíduos e como grupo (BUSSOLETTI; VARGAS, 2013).

Entretanto, nada disso seria possível no nosso trabalho, se o meio para o diálogo e experimentação para nossas ações não fossem as artes, incluindo aqui as atividades de "contação de histórias" desenvolvidas pela griô Dona Sirley. Isso significa que as artes são o terreno que nos viabiliza a desterritorialização das normas e dogmas socialmente construídos. Em nossas atividades, as artes foram essenciais para estimularem a reflexão sobre a importância de valorizar a diversidade como um fator para o desenvolvimento social. Consolidar um modelo de subjetividade que persiste e resiste na fronteira nos parece ser apropriado.

Problematizar essa nova estética surgindo dos cenários emergentes e miscigenados, onde o interculturalismo é feito como possível, significa dizer que nós ainda temos muito a fazer. Porque viver na fronteira implica, acima de tudo, em reconhecer que nós não estamos na margem de um centro, mas no centro de uma outra história (BUSSOLETTI; VARGAS, 2013). Todavia, em uma sociedade multicultural, outros aspectos precisam ser elucidados, tais como o que Pansini e Nenevé (2008) compreendem na relação do contexto educacional ao multiculturalismo historicamente formado:

[...] A educação multicultural propõe uma ruptura aos modelos pré-estabelecidos e práticas ocultas que no interior do currículo escolar produzem um efeito de colonização em que os estudantes de diversas culturas, classes sociais e matizes étnicas ocupam o lugar de colonizados e marginalizados por um processo de silenciamento de sua condição (PANSINI; NENEVÉ, 2008, p.32).

Concordando com esses aspectos, acreditamos que a possibilidade necessária de mudança de paradigmas, na direção de propostas educativas inovadoras passa pela recuperação da dimensão ética do fazer educativo aliado a uma outra estética da existência humana como princípios. Tal direção questiona e confronta assim as relações sócio-políticas e econômicas de silenciamento e se rebela contra os aviltamentos resultantes dessas relações que conduzem aquilo que Boaventura dos Santos (2005) nomina como sendo "epistemicídio":

Para além do sofrimento e da devastação indizíveis que produziu nos povos, nos grupos e nas práticas sociais que fora por ele (epistemicídio) alvejados, significou um empobrecimento irreversível do horizonte e das possibilidades de conhecimento. Se hoje se instala um sentimento de bloqueamento pela ausência de alternativas globais ao modo como a sociedade está organizada, é porque durante séculos, sobretudo depois que a modernidade se reduziu à modernidade capitalista, se procedeu à liquidação sistemática das alternativas, quando elas, tanto no plano epistemológico, como no plano prático, não se compatibilizaram com as práticas hegemônicas. (SANTOS, 2005, p.329).

Compreendemos que para uma ruptura com os modelos de produção dos silenciamentos impostos, é necessário focar a procura das vozes e conceitos silenciados, mergulhando na identificação de suas diferenças e nas problemáticas de suas adversidades, com o intuito de que as possíveis distâncias não afastem ainda mais as alteridades. Assim, nós estaríamos minimizando as dificuldades em estabelecer propostas pedagógicas eficientes, capazes de gerar identificação e significação nos mais diferentes grupos sociais.

Paola Jacques (2003), pesquisando o trabalho feito por Oiticica, identifica que este ar- 
tista criou uma proposta de "Estética da Ginga", um produto genuinamente brasileiro, em que a miscigenação e informação misturam nuances e culturas, criando um panorama que transita na ilustração de uma alegria do divertimento do carnaval. De acordo com esse preceito, a mistura e interlocução de diferentes aspectos geram uma nova informação que, pelo trânsito e movimento, como a cadência de um samba, permitem que as trocas e intercâmbios possam acontecer, se manterem ativos e constantes em sociedade (BUSSOLETTI; VARGAS, 2013). Portanto, apenas este aspecto da Estética da Ginga propiciaria aos indivíduos alcançar um estado onde o prazer, alegria, divertimento, felicidade fossem gerados pela aceitação e percepção de que as diferenças existem, mas que se abrem para possibilidades de movimento e trocas entre elas, gerando um novo colorido, que apenas enriquece as características e as relações sociais frente a um estado de respeito e apreciação de todo o espectro de matizes que constituem a identidade dessa população (BUSSOLETTI; VARGAS, 2013).

\section{6 | Considerações finais}

O trabalho de "contação de histórias" desenvolvido pela griô Dona Sirley representa mais do que apenas revelar uma parte da história brasileira que foi devastada durante o processo de colonização europeia no sul do Brasil. Esse trabalho mostra e denuncia costumes, culturas, mitologias, hábitos, religiosidades e tradições que foram silenciadas. A oralidade exercida pelos griôs funcionou e continua exercendo o seu papel através de Dona Sirley como uma estratégia fundamental para a manutenção dessas histórias de geração em geração, em um lugar onde os livros de história escritos pelos colonizadores não as permitiam.

Dona Sirley acaba por transgredir quaisquer limites por meio da liberdade poética de sua prática narrativa. Pela "contação de histórias" desenvolve uma pedagogia que transita através das fronteiras e comportamentos impostos pelas normatizações historicamente imputadas. Dona Sirley, a mestra, a griô, trabalha no sentido de manter a memória viva, promovendo um outro olhar, através da arte de contar histórias, que insiste e persiste na luta contra o esquecimento e contra o aniquilamento da experiência narrativa. Como bem disse Guimarães Rosa, as histórias não se desprendem apenas do narrador, elas o performam. Afinal, "narrar é resistir!" (ROSA, 1985, p.98).

Além disso, as atividades desenvolvidas pela griô Dona Sirley vêm ao encontro das nossas propostas de trabalho dentro da perspectiva de Estética da Ginga e Pedagogia da Fronteira. Ao contar suas histórias e realizar as suas oficinas, a griô põe em prática esses conceitos, promovendo percepções e significações sobre conceitos de diferença, diversidade, heranças culturais, como características positivas que constituem nossa sociedade e, através disso, o reconhecimento de que todas essas matizes criam a identidade da nossa população local.

Ademais, a Dona Sirley transgride quaisquer fronteiras por meio das suas atividades de "contação de histórias", desenvolvendo uma abordagem educacional que transita através das fronteiras, normas e comportamentos impostos pelas normatizações sociais, lidando com esses aspectos não como uma "divisão ou linha delimitante", mas como características que necessitam ser borradas. A Dona Sirley faz isso! A maneira como ela mantém a ancestralidade viva, promove um outro olhar para esse processo educativo, não como uma determinação acadêmica formal institucionalmente fixada, mas como uma maneira sensível, popular e cultural de manter essas tradições inesquecíveis.

Portanto, salientamos que nosso trabalho com o NALS e todos os outros projetos interligados apenas se mantêm vivos porque nós buscamos outras alternativas para promover a educação em uma outra perspectiva, buscando abordagens diferenciadas das tradições acadêmicas desenvolvidas em diversas localidades brasileiras. Nesse sentido, o campo das artes nos viabilizou a realização de todas essas atividades. Além disso, também se faz necessário re-enfatizar que o NALS também trabalha como um centro para a resistência ao fornecer o espaço que uma griô necessita para preservar uma importante parte da nossa história.

Cad. Pes., São Luís, v. 21, n. 1, jan./abr. 2014. 


\section{Referências}

BRASIL. Secretaria de Educação Fundamental.

Parâmetros Curriculares Nacionais $5^{\mathrm{a}}$ À $8^{\mathrm{a}}$ Séries: arte. Brasília, DF: MEC-SEF, 1998. p.20.

. Decreto $n^{\circ} 3.551$, de 4 de agosto de 2000. Institui o Registro de Bens Culturais de Natureza Imaterial que constituem patrimônio cultural brasileiro. Diário Oficial [da] República Federativa do Brasil, Brasília, DF, 7 ago. 2000.

. Lei $n^{\circ} 12.343$, de 2 de dezembro de 2010. Institui o Plano Nacional de Cultura. Diário Oficial [da] República Federativa do Brasil, Brasília, DF, 3 dez. 2010.

. Constituição (1988). Constituição da República Federativa do Brasil: texto consolidado até a Emenda Constitucional $n^{\circ} 68$, de 21 de dezembro de 2011. Brasília, DF: Senado Federal, 2011a.

Ministério da Cultura. Portaria $n^{\circ} 123$, de 13 de dezembro de 2011. Estabelece as metas do Plano Nacional de Cultura. Diário Oficial [da] República Federativa do Brasil, Brasília, DF, 14 dez. 2011b.

BENJAMIN, Walter. O autor como produtor. In. BENJAMIN, W. 1892-1940. Magia e técnica, arte e política: ensaios sobre literatura e história da cultura. 7. ed. São Paulo: Brasiliense, 1994. (Obras escolhidas; v. 1).

. Origem do drama barroco alemão. São Paulo:

Brasiliense, 1984

O narrador. In: BENJAMIN, W. Magia e técnica, arte e política. São Paulo: Brasiliense, 1994. (Obras escolhidas; v. 1).

BUORO, Anamelia Bueno. Olhos que pintam: a leitura da imagem e o ensino da arte. São Paulo: Cortez, 2002.

BUSSOLETTI, Denise Marcos. Narrativas populares. Brasília, DF: Conselho Nacional de Pesquisa. 2008.

BUSSOLETTI, Denise Marcos. YÁNEZ, Carlos Canal. Interculturalidade, diferença e diversidade: políticas educativas no Brasil e na Colômbia. Cadernos de Educação. v. 43. p. 138-152, 2012.

BUSSOLETTI, Denise Marcos; PINHEIRO, Cristiano Gomes. Fronteiras da diversidade: entre-lugares e desafios. Revista Querubim, v. 1, p. 44-50, 2011.

BUSSOLETTI, Denise Marcos; VARGAS, Vagner. Leituras em dramaturgia teatral para a diversidade. Pelotas: Universitária UFPEL, 2012.

Art and aesthetics of ginga: boundary for the future in the in-between places of diversity. Global Journal of Human Social Science: Arts \& Humanities, v. 13, n. 4, p. 1-9, 2013.

DUARTE JÚNIOR, J. F. O sentido dos sentidos: a educação (do) sensível. Curitiba: Crias, 2001.

FAJARDO, Elias; MATHIAS, Cristina; AUTRAN, Margarida. Papéis e panos. Rio de Janeiro: Ed. Senac Nacional, 2002.

FERNANDES, José Gulherme dos Santos. Do oral ao escrito: implicações e complicações na transcrição de narrativas orais. Outros Tempos, v. 2, p. 156-166, 2008.

GIROUX, Henry. Border crossing. Nova York; Londres, Routledge, 1992.
HAERTER, Leandro et al. O NALS no foro latino-americano memoria e identidade: respuestas nuevas a desafios bicentenários. Expressa Extensão, Pelotas, v. 2, p. 35-60, 2011.

HAMPÂTÉ BÂ, Amadou. A tradição viva. In: História geral da África, I: metodologia e pré-história da África. Editado por Joseph Ki-Zerbo. São Paulo: Ática; UNESCO, 1982. p. 181-218.

. A tradição viva. In: História geral da África, I: metodologia e pré-história da África. Editado por Joseph KiZerbo. 2.ed. rev. Brasília, DF: UNESCO, 2010. p. 167-212.

JACQUES, Paola. Estética da ginga: a arquitetura das favelas através da obra de Hélio Oiticica. Rio de Janeiro: Casa da Palavra, 2003

KI-ZERBO, Joseph. Introdução geral. In: História geral da África, I: metodologia e pré-história da África. Editado por Joseph Ki-Zerbo. São Paulo: Ática; UNESCO, 1982. p. 21-42.

KRISTEVA, Julia. Estrangeiros para nós mesmos. Rio de Janeiro: Rocco, 1994.

McLAREN, Peter. Multiculturalismo crítico. São Paulo: Cortez, 1999.

PANSINI, F.; NENEVÉ, M. Educação multicultural e formação docente. Currículo Sem Fronteiras, v. 8, n. 1, p. 31-48, 2008.

PILLOTTO, Sivia Sell Duarte. Educação pelo sensível. Linguagens - Revista de Letras, Artes e Comunicação, Blumenau, v. 1, n. 2, p. 113-127, 2007.

PINHEIRO, Cristiano Guedes; BUSSOLETTI, Denise Marcos; GILL, L. Fronteiras da cultura e da oralidade: Fórum Internacional de Contadores de Histórias e Foro Latinoamericano: Memoria e Identidad. Revista Teias, janeiro, ano 11, n. 21, p. 1-10, jan./abr. 2010. Disponível em: <http://www.periodicos.proped.pro.br/index.php/ revistateias/article/view/527/467>. Acesso em: 24 jul. 2014.

PINHEIRO, Cristiano Guedes; BUSSOLETTI, Denise Marcos; COSTA, C. Programa Fronteiras da Diversidade: universidade, comunidade na construção de práticas sociais e culturais para a diversidade. Expressa Extensão, Pelotas, v. 2, p. 79-102, 2011.

PINHEIRO, Cristiano Guedes. Narrativas de educação e resistência: a prática popular griô de Dona Sirley. 2013. Dissertação (Mestrado em Educação) - Universidade Federal de Pelotas, Pelotas, 2013.

ROSA, João Guimarães. Estas estórias. 3.ed. Rio de Janeiro: Nova Fronteira, 1985.

SANTOS, Boaventura dos. Para um novo senso comum: a ciência, o direito e a política na transição paradigmática. São Paulo: Cortez, 2005.

SCHILLER, Friedrich. A educação estética do homem. São Paulo: lluminuras, 1990.

SILVA, Gildati Guedes. A estética da sensibilidade como princípio curricular: modernidade, estética e educação sob uma perspectiva dialética. 2012. Dissertação (Mestrado em Educação) - Universidade Federal de Rondônia, Porto Velho, 2012. 